\title{
Perceptual Training Effects on the Acquisition of English Stress by Brazilian Learners
}

\author{
Andressa Brawerman-Albini ${ }^{1}$, Denise Cristina Kluge ${ }^{2}$, Adelaide H. P. Silva ${ }^{2} \&$ Luiz Carlos P. Albini ${ }^{3}$ \\ ${ }^{1}$ Modern Foreign Languages Department, Federal University of Technology - Parana, Parana, Brazil \\ ${ }^{2}$ Modern Foreign Languages Department, Federal University of Parana, Parana, Brazil \\ ${ }^{3}$ Informatics Department, Federal University of Parana, Parana, Brazil \\ Correspondence: Andressa Brawerman-Albini, Av. Sete de Setembro, 3165-80230-901, Curitiba, PR, Brazil. \\ E-mail: andbraw@utfpr.edu.br
}

Received: July 27, 2017 Accepted: August 17, 2017 Online Published: September 15, 2017

doi:10.5539/ijel.v7n6p1 URL: http://doi.org/10.5539/ijel.v7n6p1

\begin{abstract}
This study investigates the effects of perceptual training on Brazilian English language learners' ability to acquire preantepenultimate stress, or stress on the fourth to last syllable. Since preantepenultimate stress assignment is infrequent in Brazilian Portuguese (BP), it was initially hypothesized that BP speakers would store few examples of this pattern. The training was performed in five sessions and included stress identification tasks followed by immediate feedback. Results confirm the training significantly improved study participants' perception and production of preantepenultimate syllable stress assignment. Furthermore, participants generalized acquired production patterns to unfamiliar words and retained these patterns for two months after training concluded. With frequent perceptual training, it is believed BP speakers could create a new category of English words with preantepenultimate syllable stress. This study demonstrates that perception training, typically used for the perception or the production of sounds, can also be used to improve the production of L2 stress assignment with very positive results.
\end{abstract}

Keywords: perceptual training, word stress, production

\section{Introduction}

Many factors influence how native speakers judge the accents of a second language (L2) learners, including suprasegmentals like stress, rhythm, and intonation (Munro, 1995). However, according to Mareüil \& Vieru-Dimulescu (2006), research in this area has focused more on perception of segments rather than of suprasegmentals, giving little attention to the role of prosody in how L2 accents are perceived.

Kenworthy (1987) points out that native speakers typically do not understand words due to incorrect stress assignment, not mispronunciation of specific sounds. The author provides a number of examples in which misplaced stress assignment results in misunderstanding. For instance, when stress is placed on the second syllable of the word "written", it is instead understood as "retain". When the syllables com- and -ta- are stressed in the word "comfortable", the word is mistaken for the phrase "come for a table". When the syllables -duc- and -ty are stressed in the word "productivity", the listener may instead hear the phrase "productive tea".

Cruz (2011) published a series of studies which tested the intelligibility of Brazilian English learners' accents as judged by native English speakers. Based on the results of these studies, Cruz developed an original phonological model to teach pronunciation to Brazilian English learners focused on their intelligibility for native speakers. In descending order of pronunciation priorities, the steps of the model are: (1) word stress assignment variation; (2) errors due to spelling interference; (3) inappropriate consonant production; (4) inappropriate vowel production; and (5) vowel insertion. According to this model, thus, stress assignment is the most important aspect in the intelligibility of English as a foreign language. Supporting these findings, Gomes et al. (2014) investigated the intelligibility of Brazilian speakers producing suffixed words with an inadequate stress assignment by three groups of listeners: English native speakers, Brazilian speakers and non-native speakers other than Brazilians. The results showed that Brazilians' incorrect stress assignment may lead to intelligibility problems in the following order: Brazilians $>$ non-native speakers $>$ native speakers. Therefore, according to this research, non-native speakers would have even more difficulties understanding words with an inadequate stress 
assignment than native speakers themselves.

The rhythm of English is determined largely by the alternation of strong and weak syllables. English is a stress-based language with stress occurring in consistent intervals, and its rhythm derives from a steady rise and fall of strong and weak syllables. Although the distinction between these syllables is phonetic, recent research demonstrates this distinction also plays an important role in perception (Fear et al., 1995). Researchers in the area of discourse perception and speech recognition have become more interested in the role of prosody, in particular how stress affects speech decodification (Mattys, 2000). Cutler \& Norris (1988) suggest that listeners use stressed syllables as a basis for syllable separation: where there is a stressed syllable, there is a separation.

Despite the obvious importance of stress assignment and its many functions in the English language, the widespread belief that it is too difficult for students to produce English stress patterns makes it a constant afterthought in the English language classroom, and, in its absence, Brazilians struggle to acquire correct stress assignment. Still, languages like English and Portuguese require lexical stress, and stress assignment in these languages is unpredictable. When word stress is not predictable but depends on lexical identity, it is somehow included in the lexical representation associated with the particular word and must be contained in the speakers' mental lexicon (Protopapas, 2016).

Rhythm differences in the languages is another important factor that makes it even more challenging for native BP speakers to learn English stress. Fudge (1984) points out:

Because English rhythm is stress-timed, a wrong stressing will lead to a wrong and misleading rhythm (...). Comprehensibility depends on rhythm, and therefore the placing of stress within words can play a large part in determining how well a native English hearer will understand the foreign speaker (Fudge, 1984, p. 4).

Adult learners trying to acquire non-native phonemic contrasts confront the problem of a pre-existing phonological system that may interfere with the creation of new phonetic categories (Logan et al., 1991). According to Beckman \& Pierrehumbert (2000), speakers hear and produce the sounds of other languages consistent with categories formed in their first language (L1). Between the differences described above and the lack of formal rules dictating English stress assignment, the best way for non-native speakers to learn stress is through practice.

Brawerman (2006) carried out a study to examine how BP influences Brazilian English learners' production of suffixed words in English with preantepenultimate stress assignment. Because this stress pattern is rare in Portuguese (Note 1), Brazilian learners either take years to acquire it, or they simply continue to produce Portuguese stress patterns and transfer them to their English speech. The initial hypothesis of the 2006 study was that native BP speakers have a barrier around producing words with preantepenultimate stress, given their rare occurrence in BP, and therefore make substantially more mistakes when pronouncing words with this stress pattern. In the end, the study proved this hypothesis to be true. Results showed that from the thousand possible answers for each type of stress assignment, 728 were incorrect in sentences including words with preantepenultimate stress while only 117 were incorrect in sentences including words with antepenultimate stress (stress on the third to last syllable) or penultimate stress (stress on the second to last syllable). Results were similar when participants pronounced the words individually: 760 words with preantepenultimate stress were incorrectly pronounced as compared to 115 words with antepenultimate or penultimate stress.

Participants of that study explained that their trouble with English words with preantepenultimate stress was they simply had not considered the possibility of placing stress on the fourth to last syllable of a word. According to them, Brazilians do not pronounce words that way, and when the participants listen to native speakers, they are more concerned with understanding the main idea than with pronunciation. This may cause a problem. Since students rarely practice English stress assignment and lack input with examples of words with preantepenultimate stress, they cannot comprehend the possibility of stress assignment different than that found in Portuguese. The results of Brawerman's 2006 study inspired the present study, which seeks to understand how providing accurate input to Brazilian students through perceptual training influences their production of words with preantepenultimate stress.

This study parts from the hypothesis that BP speakers store few examples of words with preantepenultimate syllable stress. Due to its infrequency in BP, preantepenultimate stress is not a common or productive pattern for them. According to Bybee (2001), "the degree of productivity is determined (at least in part) by the number of items participating in a common pattern" (p. 121). The mental representation of a linguistic item is strengthened every time a speaker accesses it. Since BP speakers rarely access, use, or apply words with preantepenultimate stress, the number of representations with this stress assignment is weak. 
Due to a lack of awareness and production practice about preantepenultimate stress in the English language classroom, BP speakers have a difficult time accurately pronouncing the pattern. But how can this difficulty of preantepenultimate stress assignment be reduced if students do not have the knowledge or constant exposure to this type of word? Here, perceptual training seems to be an extremely viable alternative. Due to its ability to generate accurate input, students are able to hear the correct pronunciation of a word and pay attention to preantepenultimate stress patterns.

This study is innovative for a number of reasons (Note 2). First, the majority of perceptual training studies have been conducted in countries where English is the first language (e.g., Logan et al., 1991; Lively et al., 1993; Bradlow et al., 1997), and very few of them have carried out trainings for BP speakers (Denize-Nobre, 2007; Bettoni-Techio, 2008). Second, many perceptual training studies focus on improving perception skills (e.g., Strange \& Dittman, 1984; Wang \& Munro, 2004), but few test the transfer of improved perception to production (e.g., Wang, 2002; Yamada et al., 1996). Ultimately, among the very few studies in this area, the most notable development seems to be the research on stress perceptual training and its relation to production (Bissiri et al., 2006; Ou, 2011; Schwab \& Llisterri, 2014; Romanelli et al., 2015) (Note 3).

\section{The Importance of Frequency}

Bybee (2001) affirms that speakers store and organize examples from new input according to similarities found in previously stored examples. She argues that the frequency of use of words and certain language patterns affects the nature of mental representation, and, in some cases, the phonetic formation of words.

Experience, therefore, affects representation, and usage affects representation in memory. Bybee (2007) points out, "Repetition strengthens memory representations for linguistic forms and makes them more accessible" (p. 10). As such, speakers can more easily access high as opposed to low frequency words. In fact, if representation is too weak, it may be forgotten; hence Bybee's (2001) assertion that repetition in language is critical. She also argues that strong repetition affects phonological structures, increasing automatic production of high frequency words.

Bybee $(2001,2008)$ laid out two ways of counting the frequency in language: token frequency and type frequency. Token frequency refers to how often a unit, usually a word, appears in a text. Type frequency refers to how often a particular pattern, such as a stress pattern, an affix, or a consonant cluster, appears in a dictionary and how many distinct items each pattern represents. Consistent with this analysis, the penultimate stress pattern would be the highest frequency stress pattern of its kind in BP. In English, this pattern has the highest frequency with two syllable words, but the antepenultimate stress pattern has the highest frequency with three and four syllable words.

Frequency of use also determines a pattern's productivity, or how often it is applied to new forms. Bybee suggests that a pattern's productivity be determined to a great extent by its type frequency. This way, the more examples in the pattern's schema, the stronger it is and the more likely it is to be applied to new items. Type frequency is, therefore, relevant in determining the strength of phonological patterns like word stress assignment. According to Ellis (2002), type frequency determines productivity for three reasons. First, the more learners hear items pronounced in a specific way or position, the more likely they are to form a new category from those constructions rather than associate them with just one item in particular. Second, the more items a category has, the more general its criteria and the more likely it is to extend its criteria to new items. Finally, a high type frequency guarantees a construction's frequent use, strengthening its representation schema and making it more accessible to new items.

Bybee's (2001) categorization model also emphasizes and is strongly influenced by input. In this model, predictable characteristics are mapped and represented in memories of similar or identical past experiences while new and unpredictable characteristics create new memories. Linguistic items are organized by their observable regularities and similarities, and they are connected to a network of related items, making them easier to draw on. For example, when one word is activated, it, in turn, activates other phonetically similar words.

In usage-based theories, the role of the L1 in the acquisition of a L2 is seen as both positive and negative. When languages have similar constructions, the L1 may lay a foundation for new L2 constructions. However, even similar constructions differ in the details, and, as such, the L1 may also complicate the acquisition of complex L2 patterns. Despite these complications, sufficient input and practice combined with motivation and ability may guarantee the acquisition of non-native patterns. Therefore, while lack of exposure to native-like input complicates L2 acquisition, any learning material will naturally contain frequent constructions. To acquire less frequent constructions, both the student and teacher will need to put forth greater efforts, but as long as learners have ample exposure to L2 categories, they can use these mechanisms to facilitate their L2 learning. 
Regarding the importance of frequency in word stress assignment, Gomes et al. (2014) demonstrated that the most problematic words for Brazilians' intelligibility of words with an inadequate stress assignment were those with little token frequency or with little type frequency in their first language. Also, Waniek-Klimczac (2015) conducted a study about the factors affecting word stress recognition by advanced Polish learners of English and suggested that word frequency reflects the level of stress assignment difficulty and it is also related to learner-specific input.

The study described in this paper is grounded in the importance of frequent exposure and adequate input for the acquisition of L2 patterns. Working from this premise, perceptual training was carried out for Brazilian English learners to test their acquisition of the preantepenultimate syllable stress pattern. The subsequent sections will describe the methodology and results obtained.

\section{Methodology}

This study aims to determine if perceptual training effectively helps Brazilian English learners acquire preantepenultimate syllable stress. The five research questions are as follows:

1) Will perceptual training improve the participants' perception of preantepenultimate syllable stress?

2) Will the effects of this study be generalized for the perception of new items and new speakers?

3) Will perceptual training improve the participants' production of preantepenultimate syllable stress?

4) Will the effects of this study be generalized for the production of new words?

5) Will the production improvement be retained for two months after the training has ended?

The 30 study participants were Brazilian students majoring in Portuguese and English language arts at a federal university in the south of Brazil. They were divided in two groups: the Experimental Group (EG) with 30 students and the Control Group (CG) with ten. All EG participants had had nearly 400 hours of English instruction in their undergraduate studies while the CG participants were one or more semesters ahead with about 540 hours. The CG was used in the testing, but not in the training. Consequently, it was possible to identify if the EG's improvement was due to the training itself or to the repetition of the tests, which could have somehow become easier with time or whose answers could have been memorized.

Five American native English speakers served as interlocutors for this study, recording all stimuli present in the training and perception tests. Two of the Americans participated in the training as well as in the pre- and post-perception tests: a 51-year old woman who had lived in Brazil for 40 years, and a 38-year old man who had lived in Brazil for 12 years. The other three interlocutors were women between 25 and 40 years old who had been living in Brazil anywhere from four months to two years.

EG participants carried out all the following tasks in the span of 23 days with the exception of the retention test, which was administered about two months after the training had ended.
1) Production pre-test
2) Introductory class
3) Perception pre-test
4) Training
5) Production post-test + production generalization test with new words
6) Perception post-test + perception generalization test with new words and new speakers
7) Production retention test

\subsection{The Tests}

The study included the following tests: a pre- and post-production test, a production generalization test with new words, a production retention test, a pre- and post-perception test, and a perception generalization test with new words and new speakers.

The production tests had 40 words with preantepenultimate syllable stress as well as 20 distractor words with antepenultimate or penultimate syllable stress. Thirty of the words with preantepenultimate stress had four syllables and 10 of them had five syllables (see Table 1). The distractors and five-syllable words with preantepenultimate stress were used to check if participants would acquire accurate stress assignment after the training or make the incorrect generalization that longer words tend to have stress on the first syllable. 
Table 1. Four and five-syllable words with preantepenultimate stress

\begin{tabular}{lllll}
\hline fortunately & legislature & fascinating & capitalist & accuracy \\
virtually & architecture & calculator & militarist & modifier \\
subsequently & organizer & elevator & populism & satisfying \\
memorable & characterize & illustrator & feminism & decorative \\
noticeable & categorize & generative & citizenship & quantitative \\
reasonable & supervisor & speculative & difficulty & relatively \\
materialize & manipulative & investigator & considerable & inevitably \\
industrialize & communicative & sophisticated & particularly & administrator \\
\hline
\end{tabular}

For the production tests, the participants first read 40 sentences. Each sentence contained a word with preantepenultimate stress pre-selected for analysis. The participants then read each of the 40 words with preantepenultimate stress independently as well as 20 of the distractors with antepenultimate or penultimate stress. All 60 words were printed on cards that had been shuffled before the test to ensure randomness and avoid ordering effects.

Participants took the production post-test and the generalization test in the same sitting. For the production post-test, they were recorded saying the same group of 40 sentences containing words with preantepenultimate stress followed by the same group of 40 words with preantepenultimate stress mixed with the 20 distractors with antepenultimate or penultimate stress. The generalization test comprised 25 new words with preantepenultimate stress: 20 with four syllables and five with five syllables (see Table 2). These words had not been included in the training or heard at any point by study participants. They were selected arbitrarily to ensure randomness of all tests.

Table 2. Four and five-syllable words with preantepenultimate stress included in generalization test

\begin{tabular}{lllll}
\hline consequently & preferable & manageable & accurately & candidacy \\
permanently & admirable & favorable & nominative & popularly \\
personalize & malleable & liberator & qualitative & pacifier \\
fertilizer & comparable & mediator & legislative & championship \\
authoritative & eventually & conventionally & immediately & mysteriously \\
\hline
\end{tabular}

The retention test was carried out about two months after the production post-test, and its format mirrored that of the production pre- and post-test. The CG did not take this test as there was no knowledge to retain.

The perception tests were performed with Microsoft Access 2003. They comprised 150 stimuli, 50 words repeated three times, and were carried out in five sessions, each with 30 stimuli. These stimuli were the same 40 words with preantepenultimate stress used in the production tests (see Table 1) together with ten new distractor words with antepenultimate or penultimate stress (see Table 3).

Table 3. Perception pre- and post-test distractor words

\begin{tabular}{lllll}
\hline prejudicial & complexity & respectable & significant & democratic \\
\hline graduation & alternative & officially & immediate & familiar \\
\hline
\end{tabular}

The perception test program randomized and repeated all of these words three times. After every session, or 30 stimuli, the program showed a slide with the word "break", and the participants could choose to rest or continue with the test.

The test consisted of identification tasks, in which the participants heard a stimulus word and had to identify the stressed syllable. The test computer screen showed four or five numbered buttons, depending on the number of syllables in the word, but it did not show the written word. To identify the stressed syllable, the participants used a mouse to click on the button referring to the number of the stressed syllable. For example, if the stimulus was the word "elevator", four buttons would appear on the screen. The participant would need to click on the first button corresponding to the first syllable of the word (see Figure 1). The participants could hear the stimulus as many times as necessary by clicking on a button labeled "play again". After they selected their answer, an arrow appeared on the test screen. If they clicked on the arrow, the participants would automatically hear the next stimulus. 
When the test finished, the program would automatically generate a form with the test results. This form showed the order of the words, how many times the participants heard each word, and which button was pressed to select the answer. Participants did not have access to their test results; only the researchers were able to consult the form.

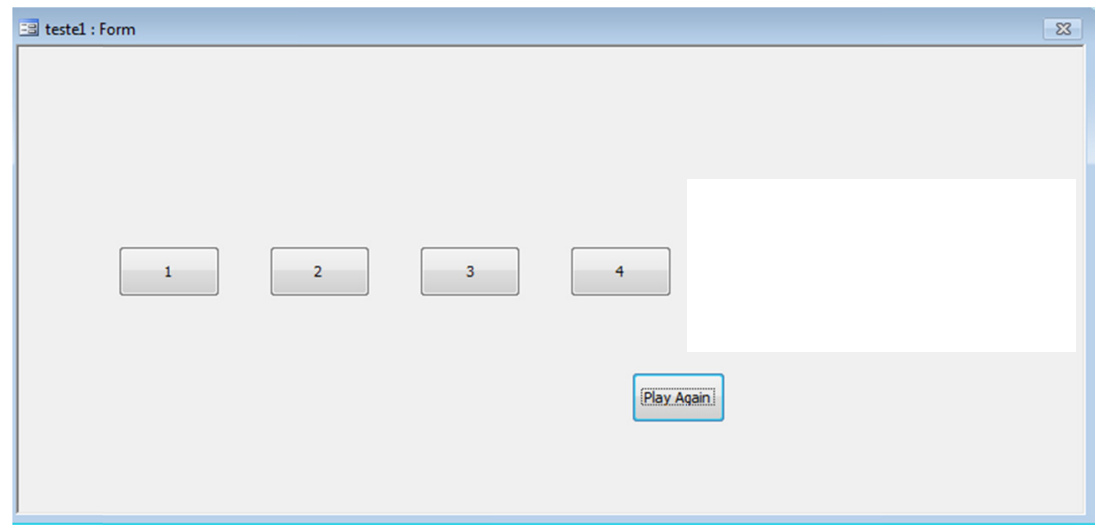

Figure 1. Example of the perception test screen

The EG performed the perception generalization test with new stimuli and new speakers on the same day as the perception post-test. The generalization test also comprised 150 stimuli (50 words repeated three times) and was also carried out in five sessions of 30 stimuli. The stimuli of this test consisted of 50 words not included in the training. Twenty-five were the same words with preantepenultimate stress used in the production generalization test, with 20 four-syllable words and five five-syllable words. The other 25 words were new selected distractor words, also with 20 four-syllable and five five-syllable words (see Table 4). The test program randomized the 150 stimuli and repeated each word three times.

Table 4. Four and five-syllable words with antepenultimate and penultimate stress included in the perception generalization test

\begin{tabular}{lllll}
\hline interruption & grammatical & stability & competitive & relationship \\
habitation & professional & captivity & participant & adaptable \\
celebration & industrial & capacity & mysterious & spectacular \\
institution & eternally & maternity & interpreter & catastrophic \\
fundamentalist & anticipation & authenticity & biographical & automatically \\
\hline
\end{tabular}

The perception generalization test not only assessed generalization of new stimuli, but also generalization of new speakers given that the three interlocutors in the generalization test were not heard at any point during the training.

\subsection{The Training}

There were 290 words which were selected for the study. Fifty of these words were randomly selected for the generalization test and were, therefore, excluded from the training and other tests.

The training consisted of 240 words total and 160 of these words had four syllables: half with pre-antepenultimate stress, and the other half with antepenultimate or penultimate stress. The other 80 words in the training had five syllables: half with pre-antepenultimate stress, and the other half with antepenultimate or penultimate stress. There were two reasons for including words with antepenultimate or penultimate stress. First, to distract the participants from over-clicking on the first syllable in the four-syllable words and on the second syllable in the five-syllable words. Second, to avoid an incorrect generalization that longer or suffixed words in English are always stressed on the first or second syllable. Five-syllable words were also included for the same purpose of avoiding an incorrect generalization that stress is always on the first syllable.

Two speakers participated in the training. Both pronounced each word once so each word was repeated twice. Each training session had 96 stimuli: 48 words with two repetitions. The training in total had 480 stimuli: 80 four-syllable words with preantepenultimate stress, 80 four-syllable words with antepenultimate or penultimate 
stress, 40 five-syllable words with preantepenultimate stress, and 40 five-syllable words with antepenultimate or penultimate stress. The training repeated each of these stimuli twice. The role of such varied stimuli was to maintain the participants' attention as well as provide a representative sample of exemplars that form a new category (Logan et al., 1991). According to Pierrehumbert (2003), "Generalizations about word-forms depend on knowing a sufficient number of words" (p. 116).

The training included identification tasks with immediate feedback. The choice to use immediate feedback is consistent with previous studies demonstrating the efficacy of this technique (e.g., Logan et al., 1991; Yamada et al., 1996; Wang, 2002; Bettoni-Techio, 2008). In the training, the participants heard the word and were asked to identify the button referring to the stressed syllable, just as in the perception tests. The training consisted of five sessions on different days divided into six blocks. Each block had 16 stimuli, thus each session had 96 stimuli (16 stimuli times six parts). The first four blocks had only four-syllable words while the last two had only five-syllable words. Each participant was allowed to hear the stimuli as many times as necessary by clicking the button "play again". After hearing the word, the participant identified the stressed syllable. If correct, the screen showed immediate feedback with the word "correct" and an arrow, which the participant clicked to proceed to the next word (see Figure 2).

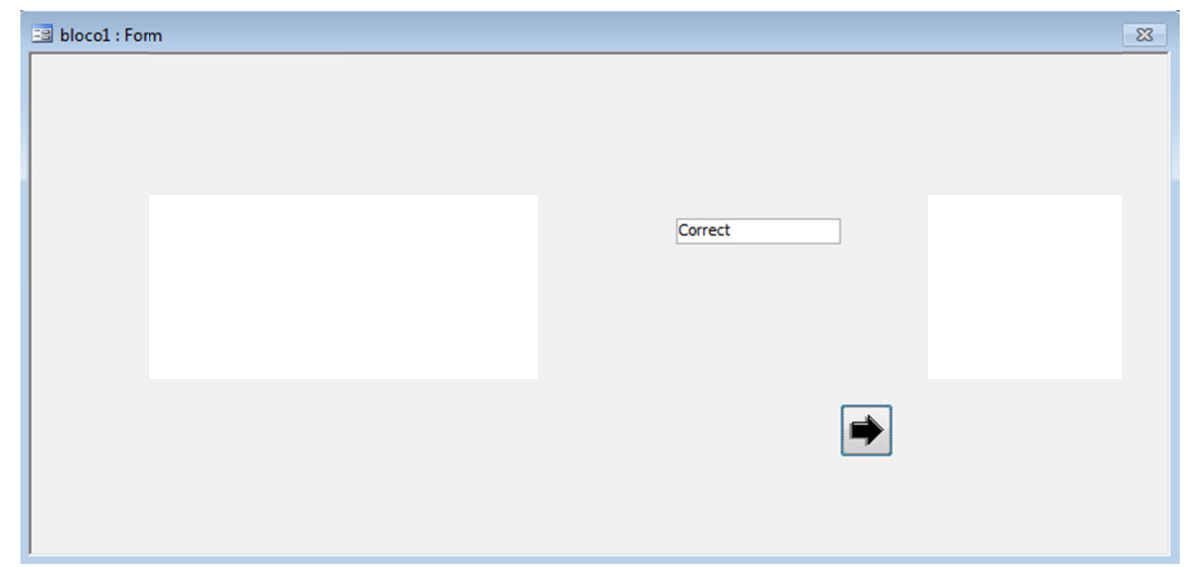

Figure 2. Example of training screen

If the participant answered wrong, the screen showed immediate feedback with the words "try again". The participant automatically heard the same word pronounced by the same speaker, but this time with additional emphasis on the stressed syllable. Feedback with emphasis on the stressed syllable was opted on account of results showed in Bissiri et al. (2006) (Note 4). Like before, the participant could hear the word as many times as necessary by clicking on the button "play again" and receive feedback of "correct" or "incorrect" once the answer was chosen. The participant, then, clicked on the arrow to proceed to the next word.

At the end of each block, the participant received feedback on how many words were correct with and without having to hear the additional stress, and how many were incorrect. After this feedback, the screen showed the word "break", and the participant could either rest or continue to the next part. At the end of each session, the program automatically generated a form showing the participant's results for that session, but only the researchers had access to this form.

\section{Results}

This section discusses the results of this study. First, the perception results will be shown and then the production results for both the EG and the CG. The discussion will be concluded by comparing the results of the two groups.

\subsection{Results for EG Perception}

Table 5 compares perception results from the pre-, post- and generalization tests with all the target words included. Figure 3 illustrates these same results. 
Table 5. GE group: Descriptive statistics of the perception of words with preantepenultimate stress in the pre-, post-, and generalization tests

\begin{tabular}{|c|c|c|c|c|c|c|}
\hline \multirow{2}{*}{$\begin{array}{l}\text { TESTS } \\
\text { Patterns }\end{array}$} & \multicolumn{2}{|l|}{ PRE- } & \multicolumn{2}{|l|}{ POST- } & \multicolumn{2}{|c|}{ GENERALIZATION } \\
\hline & Correct & Incorrect & Correct & Incorrect & Correct & Incorrect \\
\hline$\%$ Average & 85.4 & 14.6 & 95.9 & 4.1 & 93.4 & 6.6 \\
\hline Median & 91.7 & 8.3 & 97.5 & 2.5 & 94.7 & 5.3 \\
\hline Mode & $82.0^{\mathrm{a}}$ & $0.0^{\mathrm{a}}$ & 100.0 & 0.0 & 97.0 & 3.0 \\
\hline SD & 15.7 & 15.7 & 4.6 & 4.6 & 5.4 & 5.4 \\
\hline
\end{tabular}

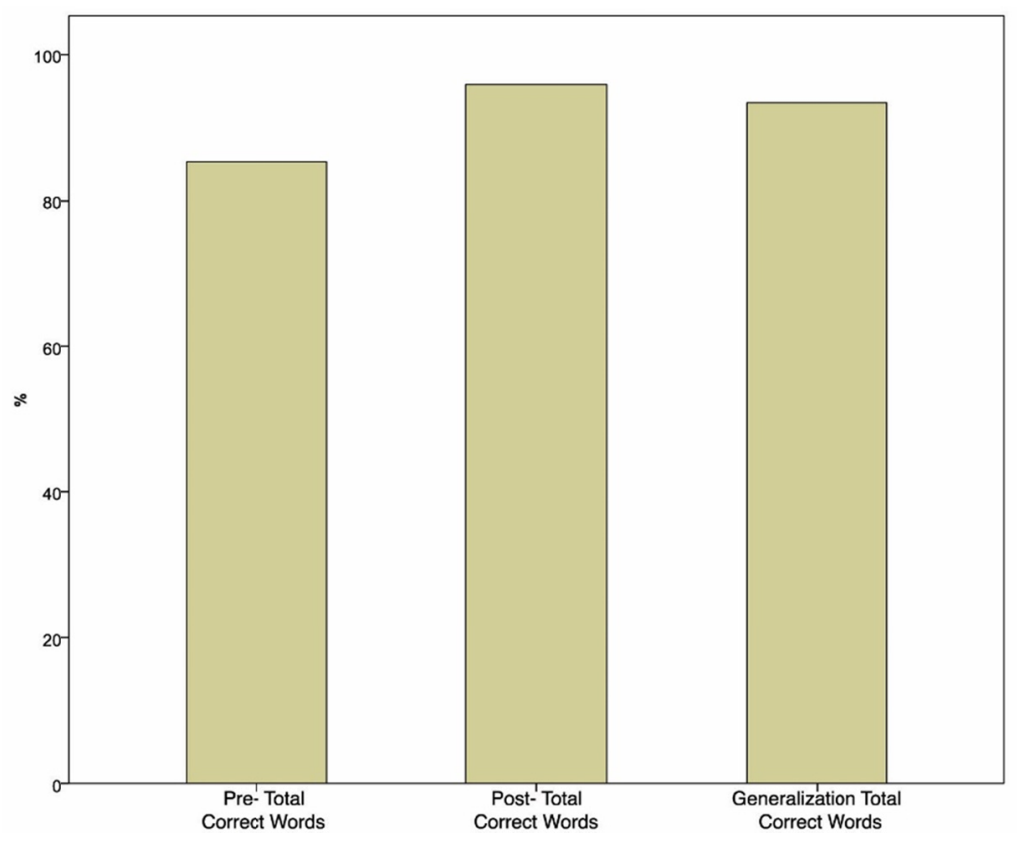

Figure 3. GE group: Total perception of words with preantepenultimate stress in the pre-, post-, and generalization tests

Results show that the correct stress pattern prevailed in all perception tests. An increase in the percentage of the correct pattern was observed from the perception pre-test to the post-test, but there was a slight fall in the result of the perception generalization test. When comparing participants' results, the Friedman test indicates considerable differences in correct pattern perception among the three tests $\left(\mathrm{X}^{2}(2, N=20)=15.108, p=0.001\right)$. The Wilcoxon test with the Bonferroni correction $(p=0.017)$ post hoc was used to explore the paired differences between the three tests and found significant differences between the pre- and post-tests $(Z=-3.434, p=0.001)$ as well as between the post- and generalization tests $(Z=-2.659, p=0.008)$.

These results suggest a substantial improvement following the training in participants' perception of preantepenultimate stress in English words, thus demonstrating the efficacy of the training. Even so, the difference between the post- and generalization tests shows that the average of the post-test is significantly higher than the average of the generalization test. This result, combined with the lack of significant differences between the pre- and generalization test $(Z=-2.254, p=0.024)$, suggests that the increase in the generalization test's percentage was not significant; that is, the ability participants acquired in the training to perceive the stress pattern was not generalized. However, an increase in the percentage of correct answers between the pre-test and the generalization test can be seen.

One possible cause for the lack of generalization is the level of the generalization test. Study participants expressed concern about the difficulty of the test, citing that the speakers of this test were harder to understand than those in the training and previous tests. For that reason, speaking variations of the interlocutors need to be taken into account.

\subsection{Results for CG Perception}

Table 6 and Figure 4 display the results of all CG perception tests with all target words. It can be observed that 
the pre- and generalization tests have the same average number of correct responses (94.3\%), but the post-test has slightly more (97.2\%). However, upon comparing the three tests without separating the number of syllables, the Friedman test indicates there were not significant differences in the averages of the correct pattern $\left(\mathrm{X}^{2}(2, \mathrm{~N}=10)=3,000, \mathrm{p}=0,223\right)$. In other words, the CG's performance did not improve during the course of the three tests. This result proves that the EG's improvement is due to the training, not the repetition of the tests.

Table 6. CG: Descriptive statistics of the perception of words with preantepenultimate stress in the pre-, post-, and generalization tests

\begin{tabular}{lllllll}
\hline TESTS & \multicolumn{2}{c}{ PRE- } & \multicolumn{2}{c}{ POST- } & \multicolumn{2}{c}{ GENERALIZATION } \\
Patterns & Correct & Incorrect & Correct & Incorrect & Correct & Incorrect \\
\hline \% Average & 94.3 & 5.7 & 97.2 & 2.8 & 94.3 & 5.7 \\
Median & 97.1 & 2.9 & 97.9 & 2.1 & 94.7 & 5.3 \\
Mode & 99.0 & 1.0 & $98.0^{\mathrm{a}}$ & $1.0^{\mathrm{a}}$ & $93.0^{\mathrm{a}}$ & $0.0^{\mathrm{a}}$ \\
DP & 5.5 & 5.5 & 2.3 & 2,3 & 5.3 & 5.3 \\
\hline
\end{tabular}

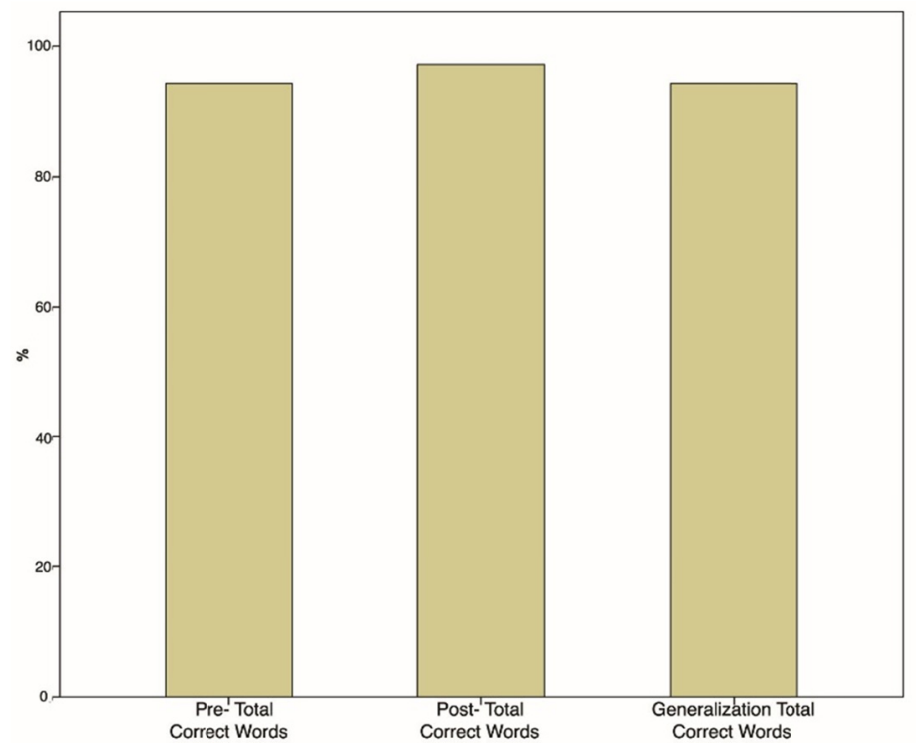

Figure 4. CG: Total perception of words with preantepenultimate stress in the pre-, post-, and generalization tests

\subsection{Results for EG production}

Table 7 and Figure 5 show the results for the total production of words with the correct preantepenultimate stress assignment in the pre-, post-, retention, and generalization tests.

Table 7. EG: Descriptive statistics of the production of words with preantepenultimate stress in the pre-, post-, retention, and generalization tests

\begin{tabular}{lllllllll}
\hline \multirow{2}{*}{$\begin{array}{l}\text { TESTS } \\
\text { Patterns }\end{array}$} & PRE- & \multicolumn{3}{c}{ POST- } & \multicolumn{2}{c}{ RETENTION } & \multicolumn{2}{c}{ GENERALIZATION } \\
\cline { 2 - 8 } \% Average & Cor. & Incor. & Cor. & Incor. & Cor. & Incor. & Cor. & Incor. \\
Median & 28.4 & 71.6 & 57.5 & 42.5 & 58.0 & 42.0 & 59.0 & 41.0 \\
Mode & 28.8 & 71.2 & 55.4 & 44.6 & 56.2 & 43.8 & 65.0 & 35.0 \\
SD & 28.0 & 72.0 & 75.0 & 25.0 & 76.0 & 24.0 & $66.0^{\text {a }}$ & $26.0^{\text {a }}$ \\
\hline
\end{tabular}




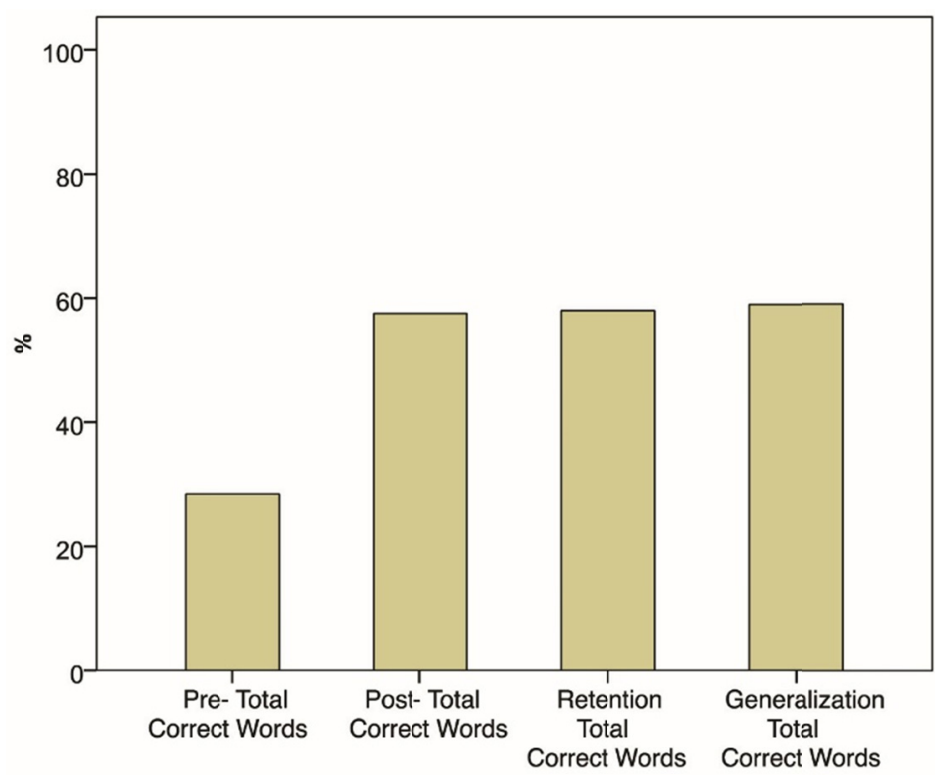

Figure 5. EG: Total production of words with the correct preantepenultimate stress pattern in the pre-, post-, retention, and generalization tests

The results show an increase in the average number of correct answers from $28.4 \%$ in the pre-test to $57.5 \%$ in the post-test followed by a slight increase in the retention test $(58 \%)$ and in the generalization test $(59 \%)$. The Friedman test was used to check if there were differences in the averages of the correct patterns in the four tests and found a significant difference among them $\left(X^{2}(3, N=20)=36.769, p<0.001\right)$. The Wilcoxon test with the Bonferroni correction $(p=0.01)$ points to a lack of significant difference between the averages of correct responses in the post- and retention test $(Z=-0.523, p=0.601)$, the post- and generalization test $(Z=0, p=1)$, and the retention and generalization test $(Z=-0.080, p=0.936)$. These results demonstrate that the improvement achieved in the post-test was generalized and maintained in the retention test.

Furthermore, the same Wilcoxon test with the Bonferroni correction $(p=0.01)$ also points to significant differences in all comparisons involving the pre-test: pre- and post-test $(Z=-3.922, p<0.001)$, pre- and retention test $(Z=-3.921, p<0.001)$, and pre- and generalization test $(Z=-3.920, p<0.001)$. The results of these tests indicate the EG's significant improvement from the pre-test to all subsequent tests. Namely, there was considerable improvement from the pre- to the post-test and this was maintained in the generalization and retention tests.

\subsection{Results for CG Production}

Table 8 and Figure 6 demonstrate CG results for the total production of words with preantepenultimate stress in the pre-, post-, and generalization tests.

Table 8. CG: Descriptive statistics of the production of words with preantepenultimate stress in the pre-, post-, and generalization tests

\begin{tabular}{lllllll}
\hline TESTS & PRE- & & POST- & & \multicolumn{2}{c}{ GENERALIZATION } \\
Patterns & Correct & Incorrect & Correct & Incorrect & Correct & Incorrect \\
\hline \% Average & 35.7 & 64.3 & 36.0 & 64.0 & 48.4 & 51.6 \\
Median & 35.8 & 64.2 & 36.2 & 63.8 & 56.0 & 54.0 \\
Mode & $25.0^{\mathrm{a}}$ & $44.0^{\mathrm{a}}$ & 44.0 & 56.0 & 5.0 & 7.9 \\
SD & 9.6 & 9.6 & 9.9 & 9.9 & & 7.9 \\
\hline
\end{tabular}




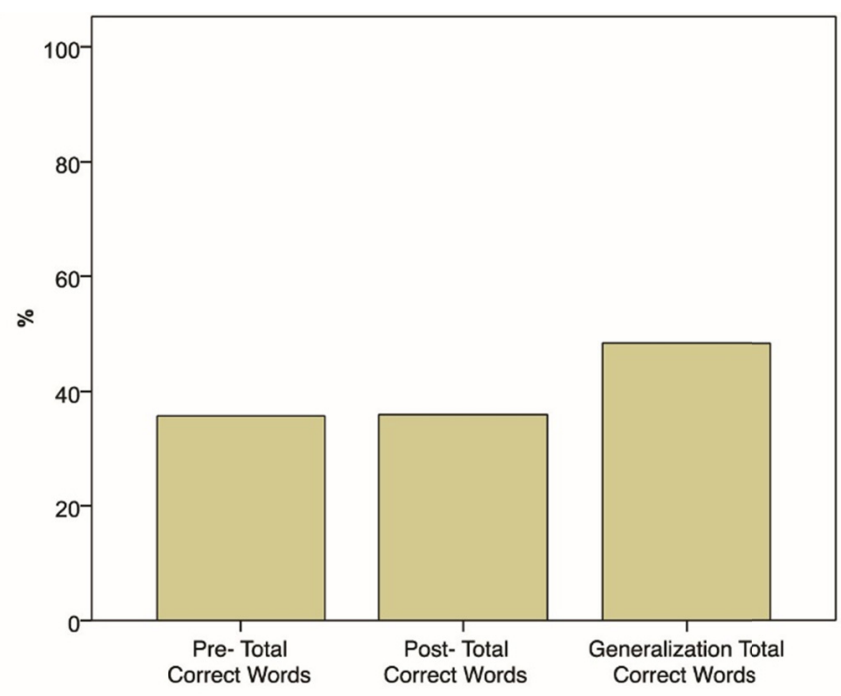

Figure 6. CG: Total production of words with preantepenultimate stress in the pre-, post-, and generalization tests

When comparing correct pattern usage, the results show similar averages in the pre- $(35.7 \%)$ and post-test (36\%) and an increased average in the generalization test $(48.4 \%)$. The Friedman test reveals significant differences in the averages of correct responses among the three tests $\left(X^{2}(5, N=10)=28.035, p<0.001\right)$. The Wilcoxon test with Bonferroni correction $(p=0.017)$ indicates a lack of significant difference between the pre- and post-test $(Z$ $=-0.140, p=0.889)$ but an occurrence of differences between the pre- and generalization tests $(Z=-2.701, p=$ $0.007)$ and the post- and generalization tests $(Z=-2.803, p=0.005)$. This shows that the results of CG pre- and post-tests are similar, with no improvement from one test to the other, whereas the results of the CG generalization test showed considerable improvement.

\subsection{Comparison between $E G$ and $C G$}

In this section, only the pre-, post-, and generalization tests are compared because the retention test was not assigned to the CG. Table 9 and Figure 7 demonstrate the EG and CG results for the total production of words with preantepenultimate stress in the pre-, post-, and generalization tests.

Table 9. EG and CG: Descriptive statistics of the production of words with the correct preantepenultimate stress pattern in the pre-, post-, and generalization tests

\begin{tabular}{lllllll}
\hline TESTS & PRE- & & POST- & GENERALIZATION & \\
Patterns & EG & CG & EG & CG & EG & CG \\
\hline \% Average & 28,4 & 35,7 & 57,5 & 36,0 & 59,0 & 48,4 \\
Median & 28,8 & 35,8 & 55,4 & 36,2 & 65,0 & 46,0 \\
Mode & 28,0 & $25,0^{\text {a }}$ & 75,0 & 44,0 & $66,0^{\text {a }}$ & 46,0 \\
SD & 12,9 & 9,6 & 18,3 & 9,9 & 16,0 & 7,9 \\
\hline
\end{tabular}




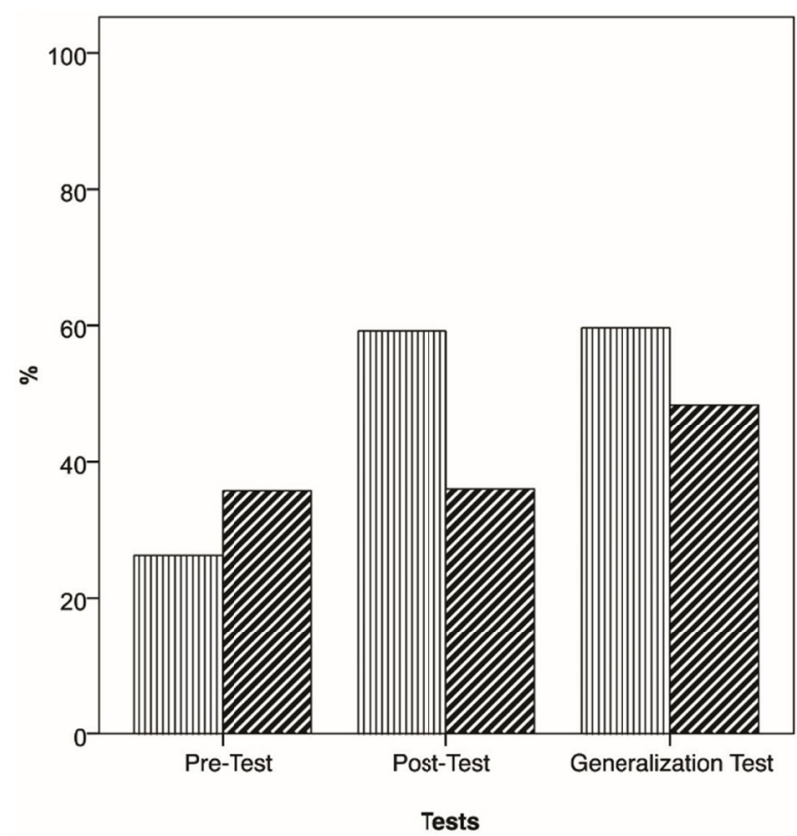

Figure 7. Comparisons of EG and CG: Total production of words with the correct preantepenultimate stress pattern in the pre-, post-, and generalization tests

These results show that the CG had a higher pre-test average (35.7\%) than the EG (28.4\%), possibly due to the CG's 140 additional hours of formal English study. Nevertheless, after the training, the EG outperformed the CG with considerably higher scores in both the post-test (GE - 57.5\% x GC - 36\%) and the generalization test (GE $59 \%$ x GC $-48.4 \%)$. The Mann-Whitney test $(p=0.05)$ was implemented to check for significant differences between the two groups in each of the tests. Although there was no significant difference in the pre-test $(Z=$ -1.299, $p=0.198)$, there was in the post-test $(Z=-3.127, p=0.001)$ and the generalization test $(Z=-2.603, p=$ 0.008 ). These results indicate that both groups were at a similar level in the pre-test, but the EG had considerably higher averages than the CG in the post- and generalization tests, demonstrating the positive effects of the training.

\section{Final Considerations}

The aim of this section is to discuss this study's results in light of Bybee's Usage-Based Phonology (2001, 2007, 2008, 2010). The results indicate the training effectively helped Brazilian English learners acquire preantepenultimate syllable stress. In the perception pre-test, the EG had an average of $85.4 \%$ correct answers. This average rose to $95.9 \%$ in the post-test and $93.4 \%$ in the generalization test. The EG's results were also positive in the transfer of knowledge from perception to production. The EG group had an average of $28.4 \%$ of correct responses in the pre-test. After the training, this average rose to $57.5 \%$ in the post-test, $58 \%$ in the retention test, and $59 \%$ in the generalization test. On the other hand, the CG had an average of $35.7 \%$ correct answers in the production pre-test, $36 \%$ in the post-test, and $48.4 \%$ in the generalization test. The results not only show a transfer of the improvement to production, but also a generalization of the acquired skill to new words and a retention of the knowledge for the two-month period.

According to the underlying assumptions of the Usage-Based Phonology, learners struggle with L2 acquisition because they have different language patterns in their L1, and they do not get as much exposure to the L2 as they do to their L1. However, since each communicative interaction stimulates the memory to strengthen existing exemplars or add new ones to a pre-existing category, adult learners' pronunciation can, in fact, undergo positive changes (Bybee, 2010). Exposure to L2 input facilitates the learning and the categorization of new patterns in memory storage where exemplars are stored close to each other. For that reason, participants in this study received repeated exposure to input of words with preantepenultimate stress. They were able to organize these examples in a new category and access this category in the moment of production.

A category of words with preantepenultimate stress may be new for BP speakers or they may have few exemplars, making it a weak category. In the Usage-Based Phonology, speakers categorize first encounters of an 
item according to similarities it shares with previously stored items. Typically, the category with the largest number of exemplars "wins" the competition and is chosen to store this new item, and the high frequency of this item reinforces the position of the category. In this way, categorization and storage of new items depends on exposure to language patterns, and it may be considered the perception training in this study generated the exposure necessary for the preantepenultimate stress pattern to be considered a type of high frequency; a pattern stored for later access in the moment of production. Furthermore, the most frequent and recently-added items create stronger mental representations, increasing their chances of being produced. This recency effect in categorization explains how participants in this study retained acquired knowledge and generalized preantepenultimate stress assignment in words excluded from the training.

The importance of type frequency predicts that each time an item is activated, it triggers other items in the same category, and, because items are organized in schema, accessing one exemplar activates similar exemplars. According to Bybee (2001), "Generalizations over forms are not separate from the stored representations of forms but emerge directly from them (...). New forms can be produced by reference to existing forms" (p. 7). Thus, the post-training generalization participants performed in this study is convincing. It can be inferred they produced new forms of words with preantepenultimate stress from stored representations of this form.

According to Bybee (2001), the frequency with which certain language patterns occur affects the nature of mental representations, making it so more frequent patterns are more strongly represented. This explains study participants' difficulty producing words with preantepenultimate stress before the training, and their relative ease in producing the same words after. In fact, if stress assignment in languages with unpredictable stress is learned merely through the speaker's use, the training gave the participants the opportunity to use these words. Participants' improvement may also be due to the vast number of words used in the training given that:

Schemas, which are organizational patterns across lexical items, gain strength from the number of different items participating - that is, by their type frequency. Stronger schemas are more productive; that is, they are more likely to be used to produce new words (Bybee, 2001, p. 28).

According to Usage-Based Phonology, speakers constantly update their mental representations. Two types of changes may exist: progressive change and conclusive change. The former is the gradual adoption of new linguistic structures in place of older ones. The latter change is consecutive, occurring after progressive change, and decisive: at this stage there are no longer two competing forms because one of them has already replaced the other. It follows that if study participants continue to be constantly exposed to words with preantepenultimate stress, this pattern can entirely replace the other forms and generate a conclusive change. Yet, if participants do not continue to be exposed to this stress pattern, the preantepenultimate category may grow weaker. It is possible participants would revert to using L1 stress patterns in English words with preantepenultimate stress, and, as a consequence, preantepenultimate stress examples would gradually disappear from their mental lexicon. A future study examining this possibility with the same study participants may lead to compelling insight.

In conclusion, study results showed significant improvement in the perception of preantepenultimate stress assignment and in the transfer of this improvement to the domain of production. This study demonstrates that perception training, typically used for the perception and/or the production of segments, can also be used to improve the production of L2 stress assignment with overwhelmingly positive results. We anticipate that this study will inspire other researchers to deepen their understanding of how perception training affects the acquisition of stress patterns, and we especially hope it encourages language teachers to take advantage of all perception training has to offer, using it as a teaching tool in their classrooms not only to the study and practice of stress patterns in particular but also to improve their pronunciation skills overall.

\section{References}

Beckman, M. E., \& Pierrehumbert, J. (2000). Positions, probabilities, and levels of categorization. Proceedings of the Eighth Australian International Conference on Speech Science and Technology, 1-18.

Bettoni-Techio, M. (2008). Perceptual training and word-initial /s/-clusters in Brazilian Portuguese/English interphonology. PhD Thesis. Universidade Federal de Santa Catarina, Florianópolis.

Bissiri, M. P., Pfitzinger, H. R., \& Tillmann, H. G. (2006). Lexical stress training of German compounds for Italian speakers by means of Resynthesis and Emphasis. Proceedings of the 11th Australian International Conference on Speech Science \& Technology, 24-29.

Bradlow, A. R., Pisoni, D. B., Yamada, R. A., \& Tohkura, Y. (1997). Training Japanese listeners to identify English /r/ and /l/: IV. Some effects of perceptual learning on speech production. Journal of the Acoustical Society of America, 101, 2299-2310. http://dx.doi.org/10.1121/1.418276 
Brawerman, A. (2006). Uma análise de erros de estudantes brasileiros de inglês na acentuação de palavras com sufixos. Master's Dissertation. Universidade Federal do Paraná, Curitiba.

Bybee, J. (2001). Phonology and language use. Cambridge: Cambridge University Press. https://doi.org/10.1017/CBO9780511612886

Bybee, J. (2007). Frequency of Use and the Organization of Language. Oxford: Oxford University Press. https://doi.org/ 10.1093/acprof:oso/9780195301571.001.0001

Bybee, J. (2008). Usage-based grammar and second language acquisition. In P. Robinson, \& N. Ellis (Eds.), Handbook of Cognitive Linguistics and Second Language Acquisition (pp. 216-236). New York: Taylor \& Francis.

Bybee, J. (2010). Language, Usage and Cognition. Cambridge: Cambridge University Press. https://doi.org/10.1017/CBO9780511750526

Cruz, N. C. (2011). Inteligibilidade fonológica de aprendizes brasileiros de inglês. Electronic Proceedings of the IX Brazilian Symposium of Applied Linguistics. Rio de Janeiro.

Cutler, A., \& Norris, D. (1988). The role of strong syllables in segmentation for lexical access. Journal of Experimental Psychology: Human Perception and Performance, 14, 113-121. http://dx.doi.org/10.1037/0096-1523.14.1.113

Ellis, N. (2002). Frequency effects in language processing: A review with implications for theories of implicit and explicit language acquisition. Studies in Second Language Acquisition, 24, 143-188. https://doi.org/10.1017/S0272263102002024

Fear, B. D., Cutler, A., \& Butterfield, S. (1995). The strong/weak distinction in English. Journal of the Acoustical Society of America, 97(3), 1893-1904. http://dx.doi.org/10.1121/1.412063

Fudge, E. (1984). English word stress. London: George Allen \& Unwin. https://doi.org/10.1017/S002222670001046X

Gomes, M. L. C., Brawerman-Albini, A., \& Engelbert, A. P. P. F. (2014). The Perception of Vowel Epenthesis and Word Stress in an English as a Lingua Franca Context. Concordia Working Papers in Applied Linguistics, 5, 185-202.

Kenworthy, J. (1987). Teaching English Pronunciation. Essex: Longman.

Lively, S. E., Logan, J. S., \& Pisoni, D. B. (1993). Training Japanese listeners to identify English /r/ and /1/: II. The role of phonetic environment and talker variability in learning new perceptual categories. Journal of the Acoustical Society of America, 94, 1242-1255. https://doi.org/10.3758/BF03206911

Logan, J. S., Lively, S. E., \& Pisoni, D. B. (1991). Training Japanese listeners to identify English /r/ and /1/: A first report. Journal of the Acoustical Society of America, 89, 874-886. http://dx.doi.org/10.1121/1.1894649

Mareüil, P. B., \& Vieru-Dimulescu, B. (2006). The contribution of prosody to the perception of foreign accent. Phonetica, 63, 247-267. http://dx.doi.org/10.1159/000097308

Mattys, S. L. (2000). The perception of primary and secondary stress in English. Perception \& psychophysics, 62(2), 253-265. https://doi.org/10.3758/BF03205547

Munro, M. J. (1995). Nonsegmental factors in foreign accent. Studies in Second Language Acquisition, 17(1), 17-33. https://doi.org/10.1017/S0272263100013735

Ou, S. (2011). Training Taiwanese EFL learners to perceive English lexical stress contrast: a pilot study. Proceedings of the 17th International Congress of Phonetic Sciences, 1550-1553.

Pierrehumbert, J. (2003). Phonetic diversity, statistical learning, and acquisition of phonology. Language and Speech, 46(2-3), 115-154. https://doi.org/10.1177/00238309030460020501

Protopapas, A. (2016). From Diacritics to the Mental Lexicon-Where is the Stress? In J. Thomson, \& L. Jarmulowicz (Eds.), Linguistic Rhythm and Literacy (pp. 237-264). Amsterdan/Philadelphia: John Benjamins Publishing Company. http://dx.doi.org/10.1075/tilar.17.11pro

Romanelli, S., Menegotto, A. C., \& Smyth, R. (2015). Stress perception: Effects of training and a study abroad program for L1 English late learners of Spanish. Journal of Second Language Pronunciation, 1(2), 181-210. http://dx.doi.org/10.1075/jslp.1.2.03rom

Schwab, S., \& Llisterri, J. (2014). Does Training Make French Speakers More Able to Identify Lexical Stress? 
Concordia Working Papers in Applied Linguistics, 5, 624-636.

Strange, W., \& Dittmann, S. (1984). Effects of discrimination training on the perception of $/ \mathrm{r}-1 /$ by Japanese adults learning English. Perception \& Psychophysics, 36(2), 131-145. https://doi.org/10.3758/BF03202673

Wang, X. (2002). Training Mandarin and Cantonese speakers to identify English vowel contrasts: long-term retention and effects on production. PhD Thesis. Simon Fraser University.

Wang, X., \& Munro, M. J. (2004). Computer-based training for learning English vowel contrasts. System, 32, 539-552. https://doi.org/10.1016/j.system.2004.09.011

Waniek-Klimczak, E. (2015). Factors Affecting Word Stress Recognition by Advanced Polish Learners of English. In E. Waniek-Klimczak, \& M. Pawlak (Eds.), Teaching and Researching the Pronunciation of English (pp. 189-204). Switzerland: Springer. https://doi.org/10.1007/978-3-319-11092-9_11

Yamada, R. A., Tohkura, Y., Bradlow, A. R., \& Pisoni, D. B. (1996) Does training in speech perception modify speech production? Proceedings of the 4th International Conference on Spoken Language Processing, 2, 606-609. https://doi.org/10.1109/ICSLP.1996.607434

\section{Notes}

Note 1. BP words are stressed in one of the last three sylabbles. Preantipenultimate stress is very rare and occurs only in words in which there is an epenthetic vowel, such as rit [i]mico and téc[i]nico.

Note 2. A first version of this paper has been published in Portuguese in: http://www.rle.ucpel.tche.br/index.php/rle/article/download/787/662

Note 3. From these studies the only one which addresses English stress is the one by Ou (2011), which only focuses on perception and not investigates production improvement.

Note 4. Bissiri's study demonstrated that utterances produced with emphasized stress are more effective ways to give feedback in stress trainings than utterances normally produced by a native speaker.

\section{Copyrights}

Copyright for this article is retained by the author(s), with first publication rights granted to the journal.

This is an open-access article distributed under the terms and conditions of the Creative Commons Attribution license (http://creativecommons.org/licenses/by/4.0/). 